\title{
Complex Electrograms Within the Coronary Sinus: Time- and Frequency-Domain Characteristics, Effects of Antral Pulmonary Vein Isolation, and Relationship to Clinical Outcome in Patients with Paroxysmal and Persistent Atrial Fibrillation
}

\author{
KENTARO YOSHIDA, M.D., MAGNUS ULFARSSON, PH.D., HIROSHI TADA, M.D., \\ AMAN CHUGH, M.D., ERIC GOOD, D.O., MICHAEL KUHNE, M.D., \\ THOMAS CRAWFORD, M.D., JEAN F. SARRAZIN, M.D., NAGIB CHALFOUN, M.D., \\ DARRYL WELLS, M.D., KRIT JONGNARANGSIN, M.D., \\ FRANK PELOSI JR, M.D., FRANK BOGUN, M.D., FRED MORADY, M.D., \\ and HAKAN ORAL, M.D.
}

From the Division of Cardiovascular Medicine, and * Department of Electrical Engineering and Computer Sciences, University of Michigan, Ann Arbor, Michigan, USA

Coronary Sinus Electrograms in Atrial Fibrillation. Background: The mechanistic and clinical significance of complex fractionated atrial electrograms (CFAE) in the coronary sinus (CS) has been unclear.

Methods and Results: Antral pulmonary vein isolation (APVI) was performed in 77 patients with paroxysmal (32) or persistent AF (45). CS electrograms recorded for 60 seconds before and after APVI were analyzed in the time- and frequency-domains. Dominant frequency (DF), complexity index (CI: change in polarity of depolarization), and fractionation index (FI: change in direction of depolarization slope) were determined. Before APVI, there was no difference in DF, CI, or FI between paroxysmal and persistent AF. APVI resulted in a significant decrease in DF, CI, and FI in all patients. Baseline CI (43 $\pm 13 / \mathrm{s}$ vs 54 $\pm 14 / \mathrm{s}$, $P=0.03)$ and FI $(64 \pm 23 / \mathrm{s}$ vs $87 \pm 30 / \mathrm{s}, \mathrm{P}=0.02)$ were lower in patients with paroxysmal $\mathrm{AF}$ who had AF terminated by ablation than who did not. At $10 \pm 2$ months, $69 \%$ of patients with paroxysmal $\mathrm{AF}$ and 49\% of patients with persistent $\mathrm{AF}$ were free from $\mathrm{AF}$ after single ablation. Baseline $\mathrm{CI}$ was higher among patients with paroxysmal AF who had AF after APVI (56 $\pm 20 / \mathrm{s}$ vs $44 \pm 10 / \mathrm{s}, \mathrm{P}=0.03)$. In patients with persistent AF, there was a larger decrease in DF after APVI among patients who remained free from AF $(13 \pm 11 \%$ vs $7 \pm 9 \%, P<0.05)$.

Conclusions: Complexity of CS electrograms may reflect drivers of AF that perpetuate paroxysmal AF after APVI. In persistent AF, the extent to which APVI decreases DF in the CS correlates with efficacy, suggesting that DF identifies patients who may require additional ablation beyond APVI. ( $J$ Cardiovasc Electrophysiol, Vol. 19, pp. 1017-1023, October 2008)

atrial fibrillation, coronary sinus, time-domain analysis, frequency-domain analysis, catheter ablation

\section{Introduction}

Complex fractionated atrial electrograms (CFAEs) may indicate atrial sites that play a role in the genesis of atrial fibrillation (AF). ${ }^{1,2}$ CFAEs are prevalent in the antral regions of the pulmonary veins (PVs). CFAEs are often targeted at other left atrial sites, particularly in patients with chronic AF. ${ }^{1-4}$ CFAEs are also commonly recorded in the coronary sinus

This study was supported in part by a grant from St. Jude Medical, Inc.

Drs. Oral and Morady are founders and stockholders of Ablation Frontiers Inc. Dr. Oral has received research grants from St. Jude Medical Inc. and Boston Scientific.

Address for correspondence: Hakan Oral, M.D., Cardiovascular Center, SPC 5853, 1500 E. Medical Center Dr., Ann Arbor, MI 48109-5853, USA. Fax: 734-936-7026; E-mail: oralh@umich.edu

Manuscript received 23 January 2008; Revised manuscript received 10 February 2008; Accepted for publication 4 March 2008.

doi: $10.1111 / \mathrm{j} .1540-8167.2008 .01175 . \mathrm{x}$
(CS). However, the mechanistic and clinical significance of CFAEs in the CS has not been well defined. For example, it is unclear whether CFAEs in the CS reflect primary drivers of AF or develop as a result of wavebreak/fibrillatory conduction, ${ }^{5}$ or from summation of electrograms from overlapping muscle fibers of the coronary sinus and left atrium. ${ }^{6}$

The purpose of this study was to better understand the mechanistic and clinical significance of CFAEs within the CS by examining: (1) their time- and frequency-domain characteristics; (2) the effects of antral pulmonary vein isolation (APVI) on CS CFAEs; and (3) the relationship between CFAEs before and after APVI and clinical outcome in patients with paroxysmal and persistent AF.

\section{Methods}

\section{Study Subjects}

The subjects of this study were 77 consecutive patients who underwent APVI for paroxysmal (32) or persistent (45) AF. The mean age of the patients was $60 \pm 10$ years. There were 57 men and 20 women. AF was first diagnosed 
$5 \pm 5$ years before referral. The mean left ventricular ejection fraction was $0.56 \pm 0.11$. The mean left atrial diameter was $39 \pm 5 \mathrm{~mm}$ in patients with paroxysmal $\mathrm{AF}$ and $47 \pm 5 \mathrm{~mm}$ in patients with persistent $\mathrm{AF}(\mathrm{P}<0.001)$. Structural heart disease was present in 43 patients (56\%): hypertensive heart disease in 26 patients, coronary artery disease in 10, and a nonischemic cardiomyopathy in seven patients. Patients who had undergone a prior ablation procedure for AF were excluded from this study.

\section{Electrophysiologic Study}

All patients provided informed written consent. Electrophysiological studies were performed in the fasting state. All antiarrhythmic medications, except for amiodarone in seven patients (9\%), were discontinued five half-lives before the procedure. Amiodarone was discontinued 6-8 weeks prior to the procedure. Vascular access was obtained through a femoral vein. A steerable quadripolar catheter with $2.5 \mathrm{~mm}$ interelectrode spacing (EP Technologies, Sunnyvale, CA, USA) was positioned in the CS and was used for recording and atrial pacing. The position of the CS catheter was confirmed periodically by fluoroscopy throughout the procedure. After transseptal puncture, systemic anticoagulation was achieved with intravenous heparin to maintain an activated clotting time of 300 to 350 seconds. The pulmonary veins (PVs) were mapped with a decapolar ring catheter (Lasso, Biosense Webster, Diamond Bar, CA, USA). An open-irrigation, 3.5-mm-tip deflectable catheter (Thermocool, Biosense Webster) was used for mapping and ablation. Bipolar electrograms were displayed at filter settings of 30 to $500 \mathrm{~Hz}$ during the procedure (EPMed Systems). Electrograms from the CS also were recorded at a band-pass of $0.5-200 \mathrm{~Hz}$ for off-line spectral analysis.

\section{Radiofrequency Catheter Ablation}

Left atrial and PV geometry was reconstructed in 3-D using an electroanatomical mapping system (Carto, BiosenseWebster) and was merged with a preacquired CT image (CartoMerge, Biosense-Webster). CFAEs within the antral regions of the right- and left-sided PVs were ablated. The endpoint of ablation was complete isolation of all PVs and elimination of all antral CFAEs. Sinus rhythm was restored by cardioversion in patients who remained in AF after APVI.

Radiofrequency energy applications had a maximum power of $35 \mathrm{~W}$ at a flow rate of $30 \mathrm{~mL} / \mathrm{min}$ and a maximum temperature of $50^{\circ} \mathrm{C}$. Near the ostium of the PVs and at posterior left atrium, the radiofrequency energy was delivered at a maximum power of $25 \mathrm{~W}$ with a maximum temperature of $50^{\circ} \mathrm{C}$.

\section{Study Protocol}

The study protocol was approved by the Institutional Review Board. Eight of the 32 patients with paroxysmal $A F$ and all of the 45 patients with persistent $\mathrm{AF}$ were in $\mathrm{AF}$ upon presentation to the laboratory. AF was induced by isoproterenol and/or rapid atrial pacing in the remaining 24 patients with paroxysmal AF.

Electrograms in the CS were recorded for 60 seconds during AF before and after APVI. Among patients in whom AF was induced, electrograms were recorded $\geq 10$ minutes after induction of AF. Baseline electrograms were recorded immediately before the first application of radiofrequency energy. In patients who remained in AF after ablation, electrograms were recorded during AF upon completion of APVI. Twentyfour patients in whom AF terminated during ablation, electrograms recorded 2 minutes before termination of $\mathrm{AF}$ were used for analysis.

\section{Digital Signal Processing}

Electrograms recorded in the CS were processed and analyzed off-line in the MatLab environment (MathWorks, Natick, MA, USA ) using custom software. First, QRS complexes were subtracted as described previously. ${ }^{7}$ The threshold for detection was defined as \pm 0.05 of the mean of the maximum 60 electrogram amplitudes in a sampling window. All data and electrograms were reviewed manually and appropriateness of detection was validated. Time- and frequency-domain analyses were performed as follows:

(i) Time-domain analysis: Because it is not clear how to best define CFAEs and the criteria for CFAEs have never been validated, two novel algorithms were developed to describe CFAEs. Instead of using arbitrary cut-off values, CFAEs were described using two continuous parameters and were compared accordingly. These parameters were complexity index (CI) based on how often depolarizations changed polarity per second, and fractionation index (FI) based on how often the direction (polarity) of the depolarization slope $(\mathrm{dV} / \mathrm{dt})$ changed per second (Fig. 1).

(ii) Frequency-domain analysis: As described previously, the dominant frequency (DF) was defined as the frequency of the highest peak of the periodogram in the interval of 0.5 to $20 \mathrm{~Hz}$ using Fast Fourier Transformation (Fig. 2). ${ }^{7}$

\section{Postablation Care and Follow-Up}

All patients were treated with intravenous heparin during an overnight hospital stay, and were discharged home the next morning on warfarin and low molecular weight heparin until the INR was $>2.0$. Patients who had been taking a rhythmcontrol drug before ablation were continued on the same drug therapy for 8-12 weeks after the procedure.

The patients were seen in an outpatient clinic 3 months after the ablation procedure and every 3-6 months thereafter. Patients were also contacted periodically by a nurse and were advised to contact the clinical center whenever they experienced symptoms suggestive of an arrhythmia. A 30day autotriggered event monitor was provided to all patients 6 months after the ablation procedure. Any episode of AF that lasted at least 30 seconds beyond 8 weeks after the ablation procedure was considered to be a recurrence of AF. Unless the patient had a history of stroke or a transient ischemic episode, anticoagulation with warfarin was discontinued at 6 months postablation if there was no evidence of symptomatic or asymptomatic $\mathrm{AF}^{8}$ The mean duration of followup was $10 \pm 2$ months.

\section{Statistical Analysis}

Continuous variables are expressed as mean \pm 1 standard deviation and were compared by Student's $t$-test or paired $t$ test as appropriate. Categorical variables were compared by Chi-square analysis or with Fisher's exact test where appropriate. A $\mathrm{P}<0.05$ indicated statistical significance.

Because one of the aims of this study was to determine the relationship between electrogram characteristics and outcome of APVI, the primary clinical outcome was freedom from recurrent $\mathrm{AF}$ in the absence of antiarrhythmic drug therapy after a single ablation procedure. 
Figure 1. Analysis of complex fractionated atrial electrogram(CFAEs) in the timedomain. A 10-second segment from a 60 second recording of electrograms within the CS is shown in Panel A. For better resolution a $300 \mathrm{~ms}$ window is magnified (Panels $B$ and $C)$. Complexity index was defined as the number of changes in polarity per second (red dots, Panel B). Fractionation index was defined as the number of changes in the direction of depolarization (polarity of $d V / d t$ ) per second (red dots, Panel C). The open green circles indicate the detection of peak electrogram amplitude. The red dots indicate effective detection points. The red lines indicate the thresholds for detection and the blue dots indicate data points below the detection threshold.
A
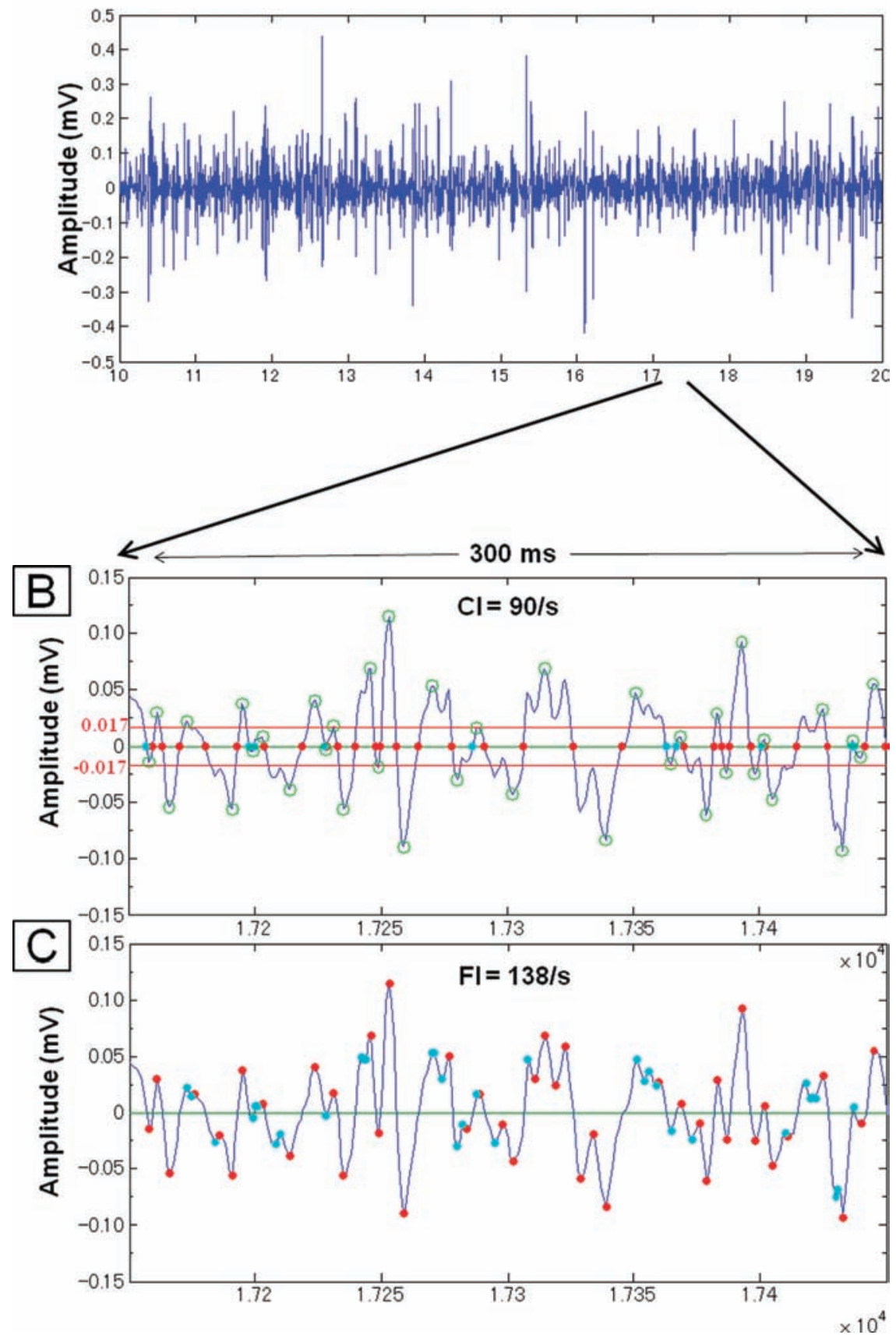

\section{Results}

\section{Time- and Frequency-Domain Characteristics of CS Electrograms Before Ablation}

The mean CI was $49 \pm 14 / \mathrm{s}$ before ablation, with no difference between paroxysmal AF (48 $\pm 15 / \mathrm{s})$ and persistent $\mathrm{AF}(50 \pm 15 / \mathrm{s}, \mathrm{P}=0.4)$. The mean FI before ablation was $82 \pm 30 /$ s. There was a trend toward a higher FI in patients with persistent $\mathrm{AF}(87 \pm 30 / \mathrm{s})$, compared with paroxysmal $\mathrm{AF}(74 \pm 28 / \mathrm{s}, \mathrm{P}=0.05$, Table 1$)$.

Comparing patients with induced versus spontaneous AF, there were no significant differences in either the mean CI $(50 \pm 14 / \mathrm{s}$ vs $44 \pm 16 / \mathrm{s}$, respectively, $\mathrm{P}=0.3)$ or the mean
FI $(76 \pm 28 / \mathrm{s}$ vs $70 \pm 30 / \mathrm{s}, \mathrm{P}=0.6)$, respectively. There was a significant correlation between CI and FI $(r=0.87$, $\mathrm{P}<0.001$, Fig. 3).

The mean DF in the CS before APVI was $6.2 \pm 0.8 \mathrm{~Hz}$. There was no significant difference in DF between patients with paroxysmal AF $(6.1 \pm 0.9 \mathrm{~Hz})$ and persistent $\mathrm{AF}$ $(6.2 \pm 0.8 \mathrm{~Hz}, \mathrm{P}=0.3)$. The DF was similar in patients with induced versus spontaneous AF $(6.0 \pm 0.9 \mathrm{~Hz}$ vs $6.1 \pm 1.0 \mathrm{~Hz}$, respectively, $\mathrm{P}=0.8$ ). There was not a significant correlation between $\mathrm{CI}$ and $\mathrm{DF}(\mathrm{r}=0.17, \mathrm{P}=0.2)$ or between FI and $\mathrm{DF}(\mathrm{r}=0.06, \mathrm{P}=0.6)$. There was no significant relationship between CI, FI, and DF and the presence or type of structural heart disease. 


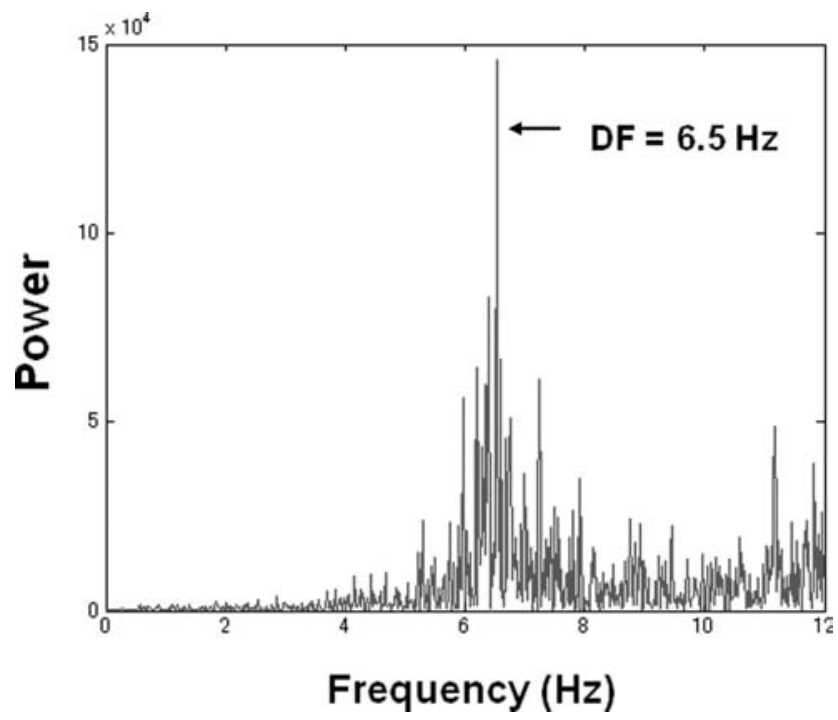

Figure 2. Dominant frequency.

\section{Effects of Antral PV Isolation}

The mean duration of radiofrequency energy application was longer in patients with persistent AF, $60 \pm 12 \mathrm{~min}$, than paroxysmal AF, $53 \pm 11(\mathrm{P}=0.007)$. There was a direct correlation between the duration of radiofrequency energy application and the percent decrease in CS DF after APVI in patients with paroxysmal $\mathrm{AF}(\mathrm{r}=0.49, \mathrm{P}=0.005)$, but not in patients with persistent $\mathrm{AF}(\mathrm{P}=0.7)$.

APVI resulted in a significant decrease in CS CI in paroxysmal AF (48 $\pm 15 / \mathrm{s}$ vs $41 \pm 13 / \mathrm{s}, \mathrm{P}=0.002)$ and persistent $\mathrm{AF}(50 \pm 15 / \mathrm{s}$ vs $42 \pm 13 / \mathrm{s}, \mathrm{P}<0.001$, Fig. 4$)$. There was no significant difference in the percent decrease in CI between patients with paroxysmal AF or persistent $\mathrm{AF}(13 \pm 19 \%$ vs $15 \pm 20 \%$, respectively $\mathrm{P}=0.6)$. There also was a significant decrease in FI after APVI $(82 \pm 30 /$ s vs $71 \pm 32, \mathrm{P}<0.001)$.

APVI resulted in a significant decrease in DF in patients with paroxysmal AF $(6.1 \pm 0.9 \mathrm{~Hz}$ vs $5.0 \pm 0.9 \mathrm{~Hz}, \mathrm{P}<$ $0.001)$ and persistent $\mathrm{AF}(6.2 \pm 0.8$ vs $5.6 \pm 0.9, \mathrm{P}<0.001$, Fig. 4). The percent decrease in DF in the CS was significantly greater in paroxysmal AF $(18 \pm 12 \%)$ than in persistent $\mathrm{AF}$ $(10 \pm 10 \%, \mathrm{P}=0.003)$.

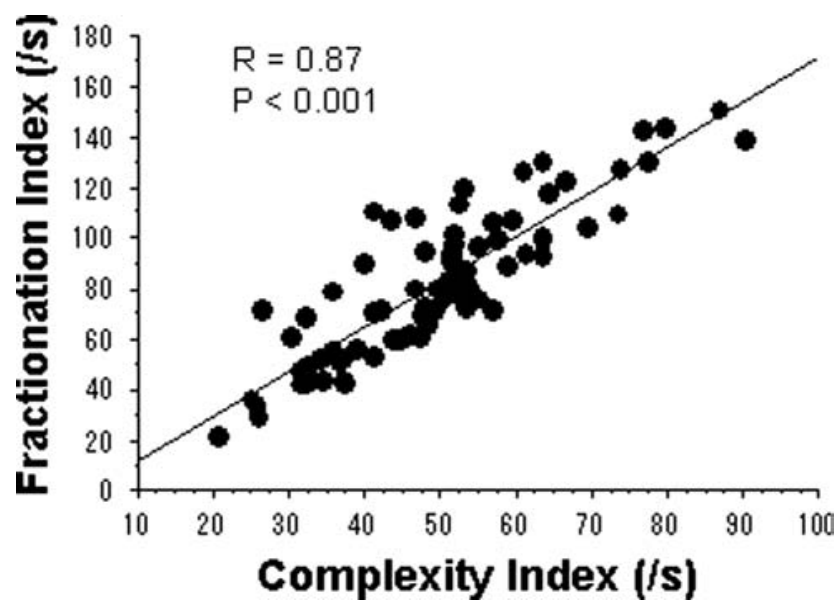

Figure 3. Relationship between the fractionation index and complexity index.

\section{Termination of AF During Antral PV Isolation}

AF terminated during APVI in 18 of 32 patients $(56 \%)$ with paroxysmal AF, and in 6 of 45 patients (13\%) with persistent AF $(\mathrm{P}<0.001)$. In patients with paroxysmal $\mathrm{AF}$, the baseline $\mathrm{CI}$ in the CS was significantly lower in patients in whom AF terminated $(43 \pm 13 / \mathrm{s})$ than in whom AF did not terminate by ablation $(54 \pm 14 / \mathrm{s}, \mathrm{P}=0.03)$. Similarly, termination of AF by APVI was associated with a lower baseline CS FI $(64 \pm 23 / \mathrm{s}$ vs $87 \pm 30 / \mathrm{s}, \mathrm{P}=0.02)$.

After APVI, the CI $(35 \pm 12 / \mathrm{s}$ vs $50 \pm 10 / \mathrm{s}, \mathrm{P}<0.001)$ and FI $(49 \pm 20 / \mathrm{s}$ vs $81 \pm 25 / \mathrm{s}, \mathrm{P}<0.001)$ were lower in patients with paroxysmal AF in whom AF terminated by ablation than in those in whom AF did not terminate by ablation.

There was no significant difference in baseline CI (47 \pm $11 / \mathrm{s}$ vs $51 \pm 15 / \mathrm{s}, \mathrm{P}=0.6)$ or FI $(80 \pm 31 / \mathrm{s}$ vs $89 \pm 30 / \mathrm{s}$, $\mathrm{P}=0.5$ ) between patients with persistent $\mathrm{AF}$ who did and did not have termination of AF during ablation, respectively.

The baseline DF in the CS was similar between patients with paroxysmal AF who did $(6.1 \pm 0.8 \mathrm{~Hz})$ and did not $(6.1 \pm 1.0 \mathrm{~Hz})$ have termination of AF during ablation $(\mathrm{P}=1.0)$. The baseline $\mathrm{DF}$ also was similar between patients with persistent AF who did and did not have AF terminated by ablation $(6.1 \pm 0.6$ vs $6.2 \pm 0.8 \mathrm{~Hz}, \mathrm{P}=0.8)$.

TABLE 1

Termination of AF, Freedom from AF and CFAEs

\begin{tabular}{|c|c|c|c|c|c|c|c|c|c|}
\hline & & \multicolumn{4}{|c|}{ Paroxysmal AF $(\mathrm{N}=32)$} & \multicolumn{4}{|c|}{ Persistent AF (N = 45) } \\
\hline & & \multicolumn{2}{|c|}{ Termination of AF During RF } & \multicolumn{2}{|c|}{ Freedom from AF } & \multicolumn{2}{|c|}{ Termination of AF During RF } & \multicolumn{2}{|c|}{ Freedom from AF } \\
\hline & & No $(N=14)$ & Yes $(N=18)$ & No $(N=10)$ & Yes $(\mathbf{N}=22)$ & No $(\mathbf{N}=39)$ & Yes $(N=6)$ & No $(N=23)$ & $\operatorname{Yes}(\mathrm{N}=22)$ \\
\hline \multirow[t]{2}{*}{$\mathrm{CI}(/ \mathrm{s})$} & Pre-RF & $54 \pm 14^{*}$ & $43 \pm 13^{*} \S$ & $56 \pm 20^{*}$ & $44 \pm 10^{*} \S$ & $51 \pm 15 \oint$ & $47 \pm 11$ & $52 \pm 16 \S$ & $49 \pm 14 \S$ \\
\hline & Post-RF & $50 \pm 10^{*}$ & $35 \pm 12 * \S$ & $48 \pm 16^{*}$ & $38 \pm 11^{*} \S$ & $42 \pm 14 \oint$ & $41 \pm 6$ & $42 \pm 13 \S$ & $42 \pm 13 \S$ \\
\hline \multirow[t]{2}{*}{$\mathrm{FI}(/ \mathrm{s})$} & Pre-RF & $87 \pm 30^{*}$ & $64 \pm 23^{*} \S$ & $88 \pm 40 \dagger$ & $68 \pm 19 \dagger \S$ & $89 \pm 30 \S$ & $80 \pm 31$ & $90 \pm 31$ & $86 \pm 29$ \\
\hline & Post-RF & $81 \pm 25^{*}$ & $49 \pm 20 * \S$ & $76 \pm 36 \dagger$ & $57 \pm 20 \dagger \S$ & $78 \pm 36 \oint$ & $70 \pm 27$ & $78 \pm 41$ & $74 \pm 28$ \\
\hline \multirow[t]{2}{*}{$\mathrm{DF}(\mathrm{Hz})$} & Pre-RF & $6.1 \pm 1.0 \S$ & $6.1 \pm 0.8 \S^{\circ}$ & $6.1 \pm 1.0 \S$ & $6.1 \pm 0.9 \S$ & $6.2 \pm 0.8 \S$ & $6.1 \pm 0.6 \oint$ & $6.4 \pm 0.8 \mp \S$ & $6.1 \pm 0.7 \ddagger \S$ \\
\hline & Post-RF & $5.0 \pm 1.0 \S$ & $4.9 \pm 0.8 \S$ & $5.0 \pm 1.0 \S$ & $4.9 \pm 0.8 \S$ & $5.7 \pm 0.9 \S$ & $5.1 \pm 0.6 \S$ & $5.7 \pm 0.9 \ddagger \S$ & $5.5 \pm 0.8 \ddagger \S$ \\
\hline
\end{tabular}

Data are shown as mean \pm SD. Freedom from AF was assessed after a single ablation procedure. AF terminated in only six patients with persistent AF. ${ }^{*}=$ $\mathrm{P}<0.05$ (for comparisons between columns), $\dagger=\mathrm{P}<0.07$ (for comparisons between columns), $\ddagger=\mathrm{P}<0.05$ (for change in $\mathrm{DF}$ ), $\S=\mathrm{P}<0.05$ for comparisons between pre- and postablation data (between the rows). $\mathrm{RF}=$ ablation, pre-RF= before ablation, post-RF $=$ after ablation. 
There was no significant difference in the percent change in $\mathrm{DF}$ when $\mathrm{AF}$ terminated during ablation and when it did not among patients with paroxysmal $\mathrm{AF}(-18 \pm 13 \%$ vs $-17 \pm$ $11 \%, \mathrm{P}=0.8)$ or persistent $\mathrm{AF}(-17 \pm 11 \%$ vs $-9 \pm 10 \%$, $\mathrm{P}=0.10)$.

\section{Electrogram Characteristics and Freedom from Recurrent $\mathrm{AF}$}

During a mean follow-up of $10 \pm 2$ months, 22 of 32 patients with paroxysmal AF (69\%) and 22 of 45 patients with persistent $\mathrm{AF}(49 \%)$ were free from recurrent $\mathrm{AF}$ and antiarrhythmic drug therapy after a single ablation procedure $(\mathrm{P}=0.08)$. Among the patients with paroxysmal AF, 15 of 18 patients $(83 \%)$ who had termination of AF during APVI, and 7 of 14 patients $(50 \%)$ who still were in AF after APVI were free from recurrent $\mathrm{AF}(\mathrm{P}=0.04)$.

The baseline $\mathrm{CI}$ in the CS was higher in patients with paroxysmal AF who had recurrent $\mathrm{AF}$ during follow-up, $56 \pm 20 / \mathrm{s}$, than in those who did not, $44 \pm 10 / \mathrm{s}(\mathrm{P}=0.03)$. There was a trend toward a higher baseline FI in patients with than in patients without recurrent $\mathrm{AF}$ after ablation $(88 \pm 40 / \mathrm{s}$ vs $68 \pm 19 / \mathrm{s}, \mathrm{P}=0.07)$.

In patients with persistent $\mathrm{AF}$, there was no significant difference in baseline $\mathrm{CI}(52 \pm 16$ vs $49 \pm 14 / \mathrm{s}, \mathrm{P}=0.5)$ or FI $(90 \pm 31 / \mathrm{s}$ vs $86 \pm 29 / \mathrm{s}, \mathrm{P}=0.6)$ between patients who did and did not have recurrent AF.

In patients with paroxysmal $\mathrm{AF}$, there was a significantly higher $\mathrm{CI}$ after APVI in patients with recurrent $\mathrm{AF}, 48 \pm 16 / \mathrm{s}$, than in patients without recurrent $\mathrm{AF}, 38 \pm 11 / \mathrm{s}(\mathrm{P}<0.05)$. The FI after APVI was $76 \pm 36 / \mathrm{s}$ and $57 \pm 20 / \mathrm{s}$ in patients with and without recurrent $\mathrm{AF}$, respectively $(\mathrm{P}=0.06)$. There was no significant difference in CI ( $42 \pm 13 / \mathrm{s}$ vs $42 \pm 13 / \mathrm{s}$, $\mathrm{P}=0.8)$ or $\mathrm{FI}(78 \pm 41 / \mathrm{s}$ vs $74 \pm 28 / \mathrm{s}, \mathrm{P}=0.7)$ after APVI among patients with persistent AF who did and did not have recurrent $\mathrm{AF}$.

There was no significant difference in baseline DF in the CS in patients with paroxysmal $\mathrm{AF}(6.1 \pm 1.0 \mathrm{~Hz}$ vs $6.1 \pm$ $0.9 \mathrm{~Hz}, \mathrm{P}=1.0)$ or persistent $\mathrm{AF}(6.4 \pm 0.8 \mathrm{~Hz}$ vs $6.1 \pm 0.7$ $\mathrm{Hz}, \mathrm{P}=0.14$ ) who did and did not have recurrent $\mathrm{AF}$ after ablation, respectively.

In patients with paroxysmal $\mathrm{AF}$, there was no significant difference in the percent decrease in DF between patients with and without recurrence of $\mathrm{AF}(18 \pm 11 \%$ vs $18 \pm 12 \%$, $\mathrm{P}=1.0$ ). However, among patients with persistent $\mathrm{AF}$, the percent decrease in DF was significantly larger in patients who remained free from $\mathrm{AF}(13 \pm 11 \%)$ than in those who had recurrent $\mathrm{AF}(7 \pm 9 \%, \mathrm{P}<0.05)$.

\section{Discussion}

\section{Main Findings}

This study demonstrates the following: (1) electrogram complexity and DF in the CS are similar in paroxysmal and persistent AF; (2) APVI decreases both the complexity and DF of CS electrograms in patients with paroxysmal and persistent $\mathrm{AF}$, but to a greater extent in patients with paroxysmal AF; (3) lesser complexity of CS electrograms in the baseline state is associated with a higher probability of termination of AF during APVI in patients with paroxysmal AF but not persistent AF; (4) a higher degree of complexity of CS electrograms at baseline is associated with a higher probability of recurrence of AF after a single ablation procedure in pa- tients with paroxysmal but not persistent AF; (5) the degree to which DF decreases after APVI correlates with a higher probability of freedom from recurrent $\mathrm{AF}$ in patients with persistent AF.

Taken together, these findings suggest that the complexity of CS electrograms reflects the presence of arrhythmogenic mechanisms of AF that extend beyond the PVs and their antra.

\section{Complexity/Fractionation Index and Dominant Frequency}

CFAEs generally have been defined as: (1) discrete electrograms that have a short cycle length, often $<120 \mathrm{~ms}(>8.3$ $\mathrm{Hz}$ ); or 2) fractionated and/or continuous electrograms. Electrograms with a short cycle length may indicate focal drivers of AF such as PV tachycardias or rotors. ${ }^{9}$ Fractionated and/or continuous electrograms may indicate slow conduction or block, and therefore are likely to reflect reentrant mechanisms. ${ }^{1}$ However, it also is possible that CFAEs simply reflect overlapping muscle fibers and/or anisotropy. ${ }^{10,11}$ It is not clear what types of CFAEs indicate primary drivers of $\mathrm{AF}$ and what types are passive phenomena.

In this study, two parameters of complexity and fractionation were analyzed as continuous variables without introducing any arbitrary criteria. The CI and FI used in this study were developed to reflect both fractionated/continuous and high-frequency electrograms, whereas the DF identifies primarily high-frequency electrograms. Furthermore, because the electrograms were sampled for 60 seconds, the data were not influenced by arbitrarily defined sampling durations of a few seconds.

\section{Characteristics of CS Electrograms}

There was no significant difference in the complexity of electrograms recorded within the CS between patients with paroxysmal and persistent AF. Consistent with the findings of a prior study, DF within the CS also was similar in patients with paroxysmal and persistent $\mathrm{AF}^{7}$ However, it has been reported that DF in the left atrium usually is higher and CFAEs in the left atrium are more prevalent in persistent than in paroxysmal AF. ${ }^{7}$ Patients with persistent AF are expected to have more electroanatomical remodeling than patients with paroxysmal $\mathrm{AF}$, and because CS electrograms were not any more complex in persistent than paroxysmal AF, it is unlikely that CFAEs within the CS develop primarily due to a result of electroanatomical remodeling. Because there was no relationship between the CI or FI and the DF within the CS in this study, CFAEs observed within the CS do not appear to be simply due to local areas of short cycle length. 5,12 Instead, CFAEs within the CS may reflect anisotropic conduction and the complex histological structure of the CS, or primary drivers in the CS. ${ }^{6,13-16}$

\section{Effects of APVI on CS Electrograms}

APVI resulted in a decrease in CI, FI, and DF in patients with paroxysmal and persistent AF. Prior studies also have demonstrated that elimination of primary drivers of $\mathrm{AF}$ in the PVs and left atrium may decrease DF or mean cycle length within the left atrium and/or CS. ${ }^{7,17}$ Possible explanations include: (1) APVI may eliminate reentrant mechanisms that utilize the CS musculature; (2) arrhythmogenic mechanisms specific to the CS may require the presence of primary drivers that originate in the PVs or left atrium. Elimination of these 

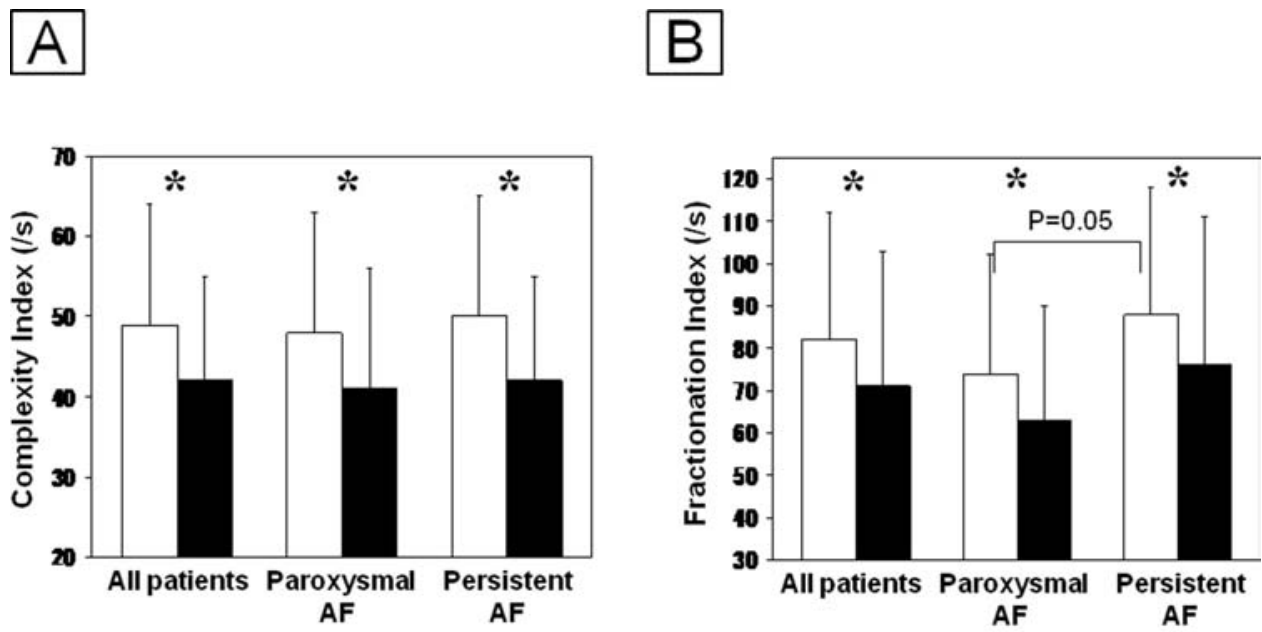

Before Ablation

After Ablation
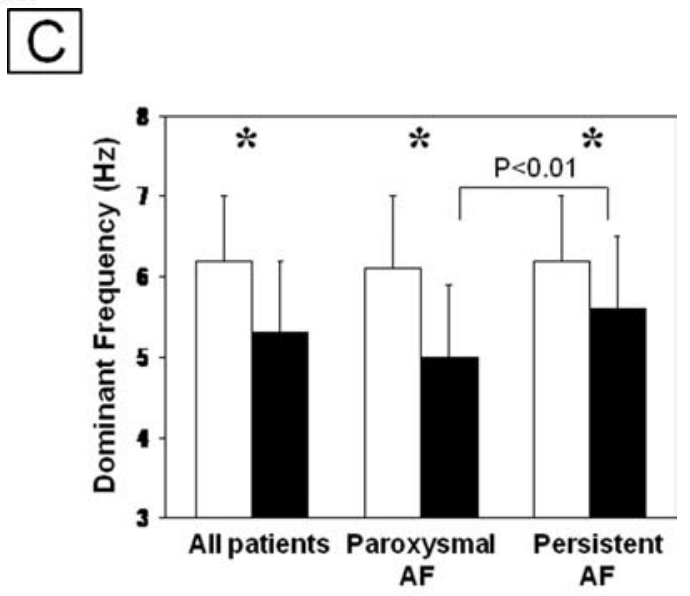

$\square$ Before Ablation

After Ablation

Figure 4. Effects of antral PV isolation on complexity index (Panel A), fractionation index (Panel B), and dominant frequency (Panel C). Patients with persistent $A F$ tended to have higher baseline FI than patients with paroxysmal AF. The percent decrease in DF after APVI was significantly greater in paroxysmal $A F$ than persistent $A F$. The DF after APVI was significantly lower with paroxysmal AF than persistent $A F{ }^{*}=P<0.05$.

primary drivers may cause secondary drivers in the CS to extinguish, similar to the dynamic interplay that occurs between the PVs and left atrium during AF: ${ }^{18}$ (3) elimination of primary drivers of AF results in a decrease in DF in the left atrium and CS. The extent to which each of these explanations contributes to the effect of APVI on CS electrograms is conjectural.

\section{Electrogram Characteristics and Termination of AF During APVI}

An association between the baseline complexity of CS electrograms and the acute and long-term response to APVI was observed in patients with paroxysmal AF. It is conceivable that mechanisms of AF not readily eliminated by APVI may be reflected in the complexity of CS electrograms in patients with paroxysmal AF.
Consistent with the findings of a prior study, there was an association between a decrease in DF after APVI and freedom from recurrent $\mathrm{AF}$ in patients with persistent $\mathrm{AF}{ }^{7}$ It is possible that most or all drivers of AF were limited to the antral regions in some patients with persistent AF. Elimination of a sufficient number of these drivers could have resulted in a greater decrease in DF and higher probability of freedom from recurrent AF.

\section{Prior Studies}

In a prior study, AF was less likely to be inducible after electrical disconnection of the CS from the left atrium following PV isolation by segmental ostial ablation in 22 patients with paroxysmal AF. ${ }^{19}$ The site of intermittent rapid tachycardia alternated between the CS and the left atrium similar to the dynamic interplay that occurs between the PVs and the left atrium. ${ }^{18}$ Consistent with these prior observations, 
the findings of this study also suggest a mechanistic role of the CS in perpetuation of AF.

In a recent study, radiofrequency catheter ablation was performed along the endocardial and epicardial aspects of the CS in 15 patients with paroxysmal AF and 40 patients with persistent $\mathrm{AF}$ who remained in $\mathrm{AF}$ after $\mathrm{PV}$ isolation. ${ }^{20}$ CS ablation was associated with termination of AF in $46 \%$ of patients with paroxysmal and $30 \%$ of patients with persistent AF. AF termination was associated with more rapid activity within the CS. Unlike in this study, the only electrogram characteristic that was analyzed was cycle length. Furthermore, the ablation strategy was limited to PV isolation without antral ablation. There was no control group of subjects who did not undergo CS ablation; and in patients with persistent AF, CS ablation was often performed in the course of additional left atrial ablation. Termination of AF during ablation within CS suggests that at least some drivers of AF utilize the musculature of the CS. Consistent with these observations, this study indicates that greater complexity of CS electrograms, particularly in patients with paroxysmal $\mathrm{AF}$, may identify those who are more likely to have drivers utilizing the CS.

\section{Limitations}

A limitation of this study is that CFAEs within the CS were not targeted for ablation, and, therefore, the clinical significance of these CFAEs cannot be proven.

Because simultaneous multisite mapping of the PVs and left atrium was not performed, the interaction between the CS and these potentially arrhythmogenic sites cannot be demonstrated.

The small number of patients with persistent AF who had termination of AF may have precluded the detection of a significant relationship between the characteristics of CS electrograms and $\mathrm{AF}$ termination.

\section{Future Directions}

Future studies are necessary to determine whether elimination of extra-PV drivers utilizing the CS improves the clinical efficacy of catheter ablation in patients with paroxysmal AF. The relationship and interdependence of drivers in the left atrium and CS remain to be examined, particularly in patients with persistent AF.

\section{References}

1. Konings KT, Smeets JL, Penn OC, Wellens HJ, Allessie MA: Configuration of unipolar atrial electrograms during electrically induced atrial fibrillation in humans. Circulation 1997;95:1231-1241.

2. Nademanee K, McKenzie J, Kosar E, Schwab M, Sunsaneewitayakul B, Vasakul T, Khunnawat C, Ngarmukos T: A new approach for catheter ablation of atrial fibrillation: Mapping of the electrophysiologic substrate. J Am Coll Cardiol 2004;43:2044-2053.

3. Oral H, Chugh A, Good E, Sankaran S, Reich SS, Igic P, Elmouchi D, Tschopp D, Crawford T, Dey S, Wimmer A, Lemola K, Jongnarangsin K, Bogun F, Pelosi F Jr, Morady F: A tailored approach to catheter ablation of paroxysmal atrial fibrillation. Circulation 2006;113:18241831.
4. Oral H, Chugh A, Good E, Wimmer A, Dey S, Gadeela N, Sankaran S, Crawford T, Sarrazin JF, Kuhne M, Chalfoun N, Wells D, Frederick M, Fortino J, Benloucif-Moore S, Jongnarangsin K, Pelosi F Jr, Bogun F, Morady F: Radiofrequency catheter ablation of chronic atrial fibrillation guided by complex electrograms. Circulation 2007;115:2606-2612.

5. Kalifa J, Tanaka K, Zaitsev AV, Warren M, Vaidyanathan R, Auerbach D, Pandit S, Vikstrom RL, Ploutz-Snyder R, Talkachou A, Atienza F, Guiraudon G, Jalife J, Berenfeld O: Mechanisms of wave fractionation at boundaries of high-frequency excitation in the posterior left atrium of the isolated sheep heart during atrial fibrillation. Circulation 2006;113:626-633.

6. Chauvin M, Shah DC, Haissaguerre M, Marcellin L, Brechenmacher C: The anatomic basis of connections between the coronary sinus musculature and the left atrium in humans. Circulation 2000;101: 647-652.

7. Lemola K, Ting M, Gupta P, Anker JN, Chugh A, Good E, Reich S, Tschopp D, Igic P, Elmouchi D, Jongnarangsin K, Bogun F, Pelosi F Jr, Morady F, Oral H: Effects of two different catheter ablation techniques on spectral characteristics of atrial fibrillation. J Am Coll Cardiol 2006;48:340-348.

8. Oral H, Chugh A, Ozaydin M, Good E, Fortino J, Sankaran S, Reich S, Igic P, Elmouchi D, Tschopp D, Wimmer A, Dey S, Crawford T, Pelosi F Jr, Jongnarangsin K, Bogun F, Morady F: Risk of thromboembolic events after percutaneous left atrial radiofrequency ablation of atrial fibrillation. Circulation 2006;114:759-765.

9. Jalife J: Rotors and spiral waves in atrial fibrillation. J Cardiovasc Electrophysiol 2003;14:776-780.

10. de Bakker JM, van Capelle FJ, Janse MJ, Tasseron S, Vermeulen JT, de Jonge N, Lahpor JR: Fractionated electrograms in dilated cardiomyopathy: Origin and relation to abnormal conduction. J Am Coll Cardiol 1996;27:1071-1078.

11. Ellis WS, Auslander DM, Lesh MD: Fractionated electrograms from a computer model of heterogeneously uncoupled anisotropic ventricular myocardium. Circulation 1995;92:1619-1626.

12. Rostock T, Rotter M, Sanders P, Takahashi Y, Jais P, Hocini M, Hsu LF, Sacher F, Clementy J, Haissaguerre M: High-density activation mapping of fractionated electrograms in the atria of patients with paroxysmal atrial fibrillation. Heart Rhythm 2006;3:27-34.

13. Ho SY, Sanchez-Quintana D, Cabrera JA, Anderson RH: Anatomy of the left atrium: Implications for radiofrequency ablation of atrial fibrillation. J Cardiovasc Electrophysiol 1999;10:1525-1533.

14. Ho SY, Anderson RH, Sanchez-Quintana D: Atrial structure and fibres: Morphologic bases of atrial conduction. Cardiovasc Res. 2002;54:325336.

15. Chen PS, Chou CC: Coronary sinus as an arrhythmogenic structure. J Cardiovasc Electrophysiol 2002;13:863-864.

16. Chen PS, Wu TJ, Hwang C, Zhou S, Okuyama Y, Hamabe A, Miyauchi Y, Chang CM, Chen LS, Fishbein MC, Karagueuzian HS: Thoracic veins and the mechanisms of non-paroxysmal atrial fibrillation. Cardiovasc Res 2002;54:295-301.

17. Haissaguerre M, Sanders P, Hocini M, Hsu LF, Shah DC, Scavee C, Takahashi Y, Rotter M, Pasquie JL, Garrigue S, Clementy J, Jais P: Changes in atrial fibrillation cycle length and inducibility during catheter ablation and their relation to outcome. Circulation 2004;109:3007-3013.

18. Oral H, Ozaydin M, Tada H, Chugh A, Scharf C, Hassan S, Lai S, Greenstein R, Pelosi F Jr, Knight BP, Strickberger SA, Morady F: Mechanistic significance of intermittent pulmonary vein tachycardia in patients with atrial fibrillation. J Cardiovasc Electrophysiol 2002;13:645-650.

19. Oral H, Ozaydin M, Chugh A, Scharf C, Tada H, Cheung P, Pelosi F $\mathrm{Jr}$, Knight BP, Morady F: Role of the coronary sinus in maintenance of atrial fibrillation. J Cardiovasc Electrophysiol 2003;14:1329-1336.

20. Haissaguerre M, Hocini M, Takahashi Y, O'Neill MD, Pernat A, Sanders P, Jonsson A, Rotter M, Sacher F, Rostock T, Matsuo S, Arantes L, Lim KT, Knecht S, Bordachar P, Laborderie J, Jais P, Klein G, Clementy J: Impact of catheter ablation of the coronary sinus on paroxysmal or persistent atrial fibrillation. J Cardiovasc Electrophysiol 2007; 18:378-386 